\title{
ASSESSMENT IN TEXTBOOKS: EXPLORING COGNITIVE DEMAND IN FIRST-YEAR ACCOUNTING TEXTBOOKS
}

\author{
J. C. Ngwenya* \\ e-mail:ngwenyaj@ukzn.ac.za \\ O. O. Arek-Bawa* \\ e-mail: orheab@gmail.com \\ ${ }^{*}$ Commerce Education Department \\ University of KwaZulu-Natal \\ Durban, South Africa
}

\section{ABSTRACT}

The South African higher education program expects to develop graduates with high cognitive skills. This is endorsed further by the expectations of high cognitive attributes for entry level members from the Accounting professional bodies. Although learning is largely driven by assessment, relatively few studies have investigated assessments in Accounting textbooks. Furthermore, most used Bloom's taxonomy as their sole analytical lens. Using a Revised Bloom's taxonomy and Leong's levels of difficulty hybrid framework, this article examines the cognitive challenge of assessment tasks in selected level-one Financial Accounting textbooks used in South Africa and Kenya. The findings reveal the dominance of the Apply-Task-Hybrid and the possibility of enabling higher cognitive attributes within lower levels of cognition. The article provides new insight for accounting academics who seek to enhance their pedagogical engagement, as well as textbook producers, curriculum developers and professional accounting bodies. It also offers the Layered Analytical Framework as an alternative approach to examining cognitive demand across diverse fields of study, but specifically within the discipline of Accounting.

Keywords: assessment task in Accounting textbooks, Revised Bloom's Taxonomy, cognitive demand, higher education, Levels of Difficulty.

\section{INTRODUCTION}

In South Africa, the National Qualifications Framework stipulates that assessments should be done to nurture high cognitive skills in an integrated manner (SAQA 2012; Bezuidenhout and Alt 2011). Similarly, the Commission for University Education (CUE) in Kenya requires that the undergraduate degree programme equips students with diverse cognitive abilities applicable in diverse settings (CUE 2014). By implication, higher education accounting curricula ought to train students to develop these attributes. One way of achieving this aim is through the use of textbooks, particularly in developing countries where it remains a primary resource in the 
teaching space (Opoku-Amankwa 2010).

However, research on textbooks in Accounting has been relatively scarce (Chiang et al. 2008; O'Reilly-Bargate 2008; Gupta and Marshall 2010), especially in relation to Cognitive Demand (CD) of the assessment tasks in these textbooks, although it is widely known that assessment is primary determinant of learning (Bezuidenhout and Alt 2011). Apart from Stokes (2008) and Stokes, Rosetti and King (2010), who examined this phenomenon in introductory accounting textbooks, other studies, all based in the developed world context, have mainly addressed assessment tasks in intermediate and advanced level textbooks. Thus, accounting academics may not be able to verify the degree to which the assessments in these textbooks can develop the cognitive attributes of their students in readiness for the workplace. This is a serious gap to be addressed.

To what extent do Financial Accounting textbooks develop the reasoning skills amongst first-year Accounting students? This article examines assessment tasks in two textbooks used by two higher education institutions (HEIs) in South Africa and Kenya, aimed at understanding the CD contained therein. It employs the Layered Analytical Framework (LAF) to illuminate the nuances in cognition embedded in different assessment tasks. Thus, it seeks to answer the question raised, along the following structural lines: 1) Background and review of current literature and concepts; 2) Methodology; 3) Data presentation and discussion, and 4) Further discussions and conclusions.

\section{BACKGROUND AND REVIEW OF RELEVANT LITERATURE AND CONCEPTS}

For graduates to make an effective impact in the knowledge economy, the undergraduate programme should acquaint them with the ability to "think well" (Jones and Davidson 2007). Indeed, the accounting curriculum in approved institutions of higher learning in South Africa and Kenya, which draws heavily on the syllabus of professional bodies, is meant to equip college students with the technical knowledge of the discipline. However, it should also enable students to develop other pervasive skills inclusive of intellectual abilities (South African Institute of Chartered Accountants, (SAICA) 2017; International Accounting Education Standards Board, (IAESB) 2010). Intellectual abilities incorporated within professional skills expectations include the capacity to critically scrutinize data, resolve issues and communicate well (SAICA 2017). In other words, accounting curricula should be delivered in a manner that enables the development of higher order thinking skills. These skills should empower students to think analytically and critically, proffer creative solutions to unstructured problems, and make sound judgements in the real world (IAESB 2010; CUE 2014). 


\section{Textbooks in developing countries}

Textbooks are regarded as essential inputs in the curriculum especially in developing countries where they tend to be the most economical way of enhancing the value of education (Agrawal et al. 2011). Where teachers have poor content knowledge with limited access to curriculum documents, the textbook becomes a major source of support that backs up the teacher's explanations (Greaney 2006; Kasule 2011). Although some textbooks are criticised on qualityrelated issues, clarity of language and insufficient information, they are still the foremost avenue for communicating knowledge not only to students as they are found to be useful to the whole family (Agrawal et al. 2010; Mahadi and Shahrill 2014). Thus, academics place considerable reliance on textbooks to aid the predominant lecture teaching method (Davidson and Baldwin 2005; Okafor 2012) that provides sequence, content and assessments.

\section{Assessment in accounting textbooks}

It is argued that to prepare students for the complexities in the business environment, assessment tasks in accounting textbooks should go beyond recall and comprehension of disciplinary concept to include analysis, synthesis and evaluation of data (Gupta and Marshall 2010; Bezuidenhout and Alt 2011). However, literature reveals paucity of scholarly work pertaining to assessments (Davidson and Baldwin 2005). Most of the studies on the CD of assessment activities in these textbooks have mainly focused on End of Chapter (EOC) materials in accounting textbooks used in the second and third years of study via Bloom's taxonomy (Davidson and Baldwin 2005; Gupta and Marshall 2010). Scholars have concluded that the EOC materials do not sufficiently foster high level thinking skills, as the bulk of these tasks addressed middle order thinking skills of application and analysis. At introductory levels, Stokes (2008) and Stokes, Rosetti and King (2010), concluded that the assessment activities targeted lower-order cognitive abilities when they investigated the congruency of learning objectives with assessment tasks. Within the African continent, save for publications (ArekBawa and Dhunpath 2017) affiliated with doctoral study (Arek-Bawa 2018), researchers have examined only readability in accounting texts (O'Reiley-Bargate 2008) and textbook selection criteria (Bargate 2012). The above review reveals the paucity of research in this area, while pointing to the need for a deeper understanding of $\mathrm{CD}$ of assessments in higher education accounting textbooks utilised within African.

\section{Cognitive demand}

Cognitive Demand is viewed differently by different scholars. Some consider CD as the level or kind of thinking involved in satisfactorily resolving a problem (Henningsen and Stein 1997). 
Others such as Park (2011), regard CD as the quantity of intellectual activity needed to proffer accurate solutions to a question. Schultz (2009), however, sees CD as cognitive engagement which entails both type and quantity of thinking. Thus, CD can be viewed in terms of "type" or "level" of reasoning and in terms of "quantity" of thinking required to offer suitable answers to questions or tasks. To gain a robust insight into the phenomenon, this article draws on both views to define $\mathrm{CD}$ as the type and quantity of intellectual activity required in resolving a problem satisfactorily. By examining the CD of the assessment tasks in textbooks, one can categorize the extent and level of reasoning that occurs in a student's mind. One way of assessing CD in assessment tasks is with educational taxonomies such as the Revised Bloom's Taxonomy (RBT).

\section{The revised taxonomy}

The original Bloom's taxonomy was revised in 2001 to incorporate conceptual advancement in education that had taken place since it was published in 1956 (Anderson et al. 2001). The RBT comes in two aspects - the Knowledge Dimension and Cognitive Process.

The Knowledge Dimension encompasses four main types:

- Factual Knowledge is described as discrete facts, elements and terms with which students must be acquainted (Anderson et al. 2001). It comprises knowledge of terminologies and precise details and elements. Example include diverse accounting terms.

- Conceptual knowledge dwells more on the inter-relationships among variables/basic knowledge elements and larger structures, rather than discrete information (Anderson et al. 2001). It encompasses knowledge of classifications and categories, principles and generalizations, and theories, models and structures. Examples comprise various accounting concepts.

- Procedural knowledge is the knowledge of how to do things relating to methods, techniques and processes (Anderson et al. 2001). It includes knowledge of subject-specific skills and algorithms; subject-specific techniques and methods, and criteria for determining when to use appropriate procedures. Examples would include journal entries, financial statements and ledger accounts.

- Meta-cognitive knowledge is described as general cognition as well as self-cognition, including contextual and provisional knowledge. 
The Cognitive Process Dimension comprises six reasoning processes:

- At the first level, Remember, is described as the ability to retrieve information from longterm memory via recall and recognition (Anderson et al. 2001). An example could include making a list of current assets.

- The second level, Understand, entails making meaning of relevant communication in any format through interpreting, exemplifying, classifying, summarising, inferring, comparing or explaining (Anderson et al. 2001). At this level, students could be required to explain the objectives of financial statements.

- $\quad$ The third level, Apply, involves the use of previously acquired learning in a different situation which could be familiar/routine (execute) or unfamiliar (implement) (Anderson et al. 2001). An example would involve the preparation of ledger accounts.

- The fourth level, Analyse, describes the ability to break-down information, find relationships between different parts and determine how the parts fit into a whole (Anderson et al. 2001). It comprises of differentiating, organising, and attributing. Performing different forms of reconciliation would fall into this category (Arek-Bawa and Dhunpath 2017).

- The fifth level, Evaluate, entails making discernment on the basis of a criteria which could be internal i.e. checking, or external i.e. critiquing (Anderson et al. 2001). An example could include deciding on a suitable investment option.

- The final level, Create, involves combining elements to make something new or novel, sub-categorised as generating, planning and producing (Anderson et al. 2001). Developing an internal control strategy for a business could fall under this category.

Although the RBT offers the framework for gaining insight into the level of CD in a task, it is found wanting in explaining $\mathrm{CD}$ emanating from other parameters including quantity. This article therefore draws on aspects of Leong's (2006) conceptualisation of levels of difficulty to obtain a better understanding of CD.

\section{Levels of Difficulty (LOD)}

From four parameters of difficulty conceptualised by Leong, this article infuses content and task parameters with the RBT to obtain a more robust understanding of CD.

Content difficulty pertains "to the difficulty of the subject matter such as facts, concepts, principles and procedures" (Leong 2006, 3), which was classified into three categories. The 
first is the "basic" category which relate to contents that students have learnt in their earlier years and are therefore more familiar with. Such items may not be difficult for many students because of repeated engagement with them (Berger, Bowie and Nyaumwe 2010; Le Hebel et al. 2017). Next are level-appropriate contents which the author termed "adequate", followed by those termed "advanced" because they relate to knowledge elements that will be given greater depth subsequently (Leong 2006). Other variables such as the number of the knowledge elements assessed also have an impact on the difficulty of the subject matter, as attested to by scholars (Ahmed and Pollitt 1999; Zingaro, Petersen and Craig 2012).

Task difficulty is described as the difficulty that students face in their attempt to resolve a problem satisfactorily. Apart from the difficulties entrenched in the cognitive involvement, Leong 2006 asserts that the Number-Of-Steps (NOS) needed in resolving a task can make it more or less difficult irrespective of the cognitive level involved. Scholars (Leong 2006; Sheard et al. 2013) allude that the more the steps, the more difficult the task. Furthermore, task difficulty can be examined based on the guidance incorporated in the question. Assessment items that contain scaffolds that guide students on how to accomplish them are normally less difficult compared with those without (Sheard et al. 2013).

\section{METHODOLOGY}

This article uses a Qualitative Content Analysis (QCA) methodology to enable a rich interpretation of the CD. QCA makes room for the development of an analytical framework from theory (Marsh and White 2006), which was done in this research. The LAF is not just a combination of the attributes of the RBT and the LOD: it is a sophisticated analytical tool that illuminates varied demand on cognition that would otherwise go unnoticed. QCA is widely used in document analysis (Forman and Damschroder 2008; Elo et al. 2014), because it paves way for an in-depth understanding into the content.

In selecting the textbooks, consideration was given to texts used by first-year college students in highly ranked higher education institutions both South Africa and Kenya. In South Africa, the selected text labelled, Textbook X, was also the most widely used textbook amongst SAICA-accredited institutions in 2014. The Kenyan book is tagged Textbook Y. Since it was not practical to review every assessment in the textbooks (Davidson and Baldwin 2005), we have included chapters that are theoretical and numerical to capture diverse cognitive manifestations. Like Chiang et al. (2008), we have classified the chapters in the textbooks into four categories (introductory content; basic accounting content; more technical content; and financial statements) prior to selecting a chapter with similar content from each of these categories for further scrutiny. In total, we reviewed a minimum of 20 per cent of the content 
in each textbook.

In each textbook, we examined Inter-Textual (IT) assessment activities that unfold as the topic progresses, the EOC items and questions contained in the Question Book (QB) where applicable. Each part of a question with more than one part was treated as a separate question. Criteria for the evaluation of the assessment tasks were developed based on the levels of both dimensions of the RBT discussed above, in addition to the two parameters (task and content), LOD. The analytical framework developed from both theories gave rise to multiple hybrids such as the Apply-Task-Hybrid with various sub-hybrids, as seen in the next section.

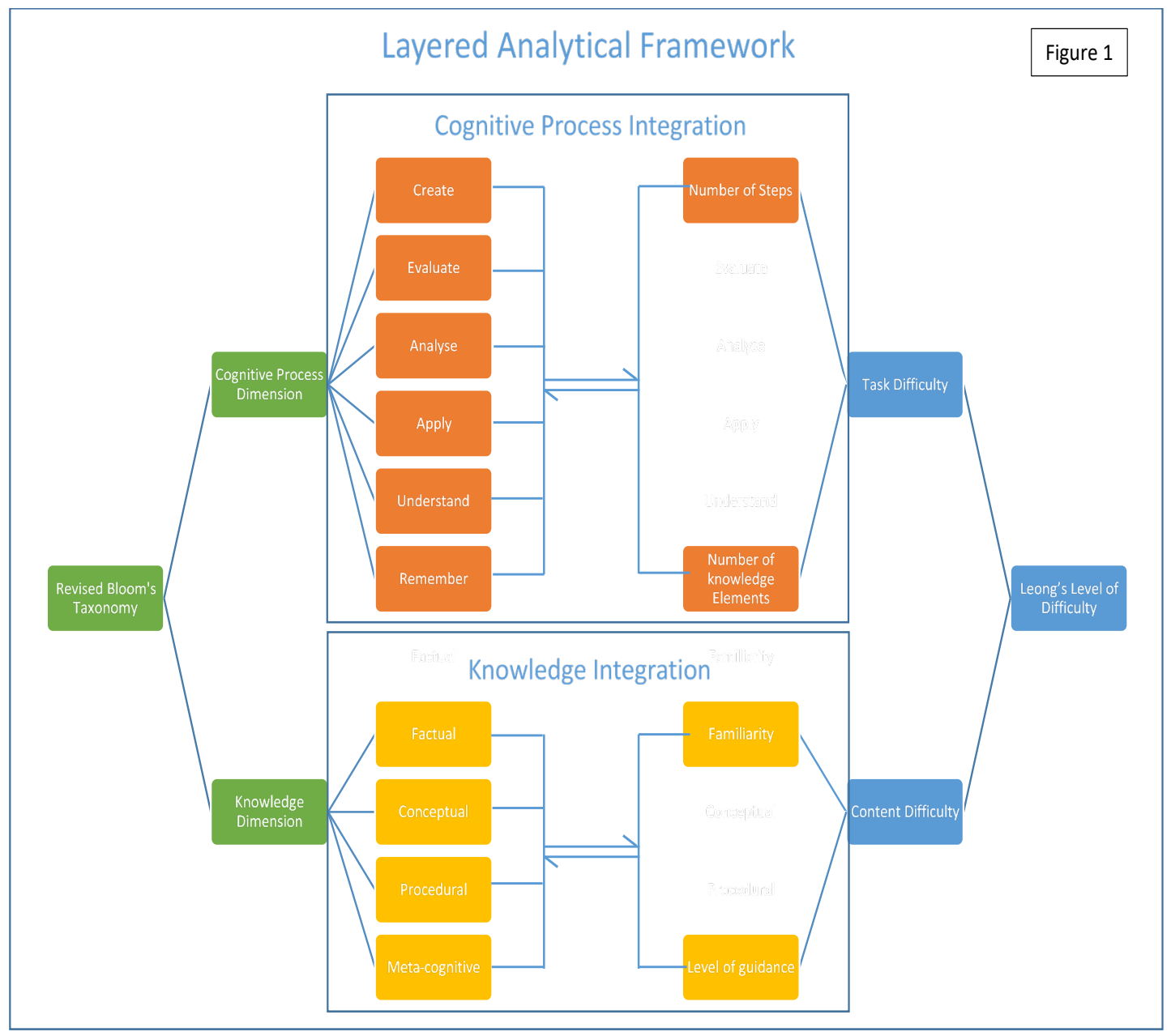

Figure 1: Layered Analytical Framework (LAF)

Trustworthiness was enhanced through repeated coding, reading and member checks by the UKZN higher education cohort and supervisors.

\section{FINDINGS AND DISCUSSION}

Table 1 shows the outcome of our analysis of two textbooks through the lens of the LAF, which resulted in six hybrids. Each hybrid encompassing three sub-hybrids reveal the result of 
variations within cognitive levels based on distinct variables from the LOD. For instance, the Understand-Content-Task hybrid had a total of 144 assessments of which 97 were subcategorised as "basic" using the "Number Of Knowledge (NOK) elements" criterion. 16 were termed "moderate" while the advanced sub-hybrid contained only one assessment activity. Additionally, about 54 per cent of the assessment tasks in the Understand-Content-Task hybrid addressed factual knowledge and 46 per cent assessed conceptual knowledge.

The first, second and third hybrids in terms of dominance comes from the middle-, lower- and higher-levels of cognition respectively. From the data, the Apply-Task-Hybrid (ATH) stood out as the most significant hybrid in total, as it accounted for about 51 per cent of the total cognitive representation. Next was the Understand-Content-Hybrid with a 25 per cent coverage, while the hybrid linked to Evaluate (9\%), Remember (8\%) and Analyse (7\%) categories shared a fairly even spread. Sadly, the hybrid associated with the highest cognitive process (Create) contained a lone assessment activity.

Table 1: Overview of the cognitive distribution of the assessment tasks in Texts $A$ and $C$

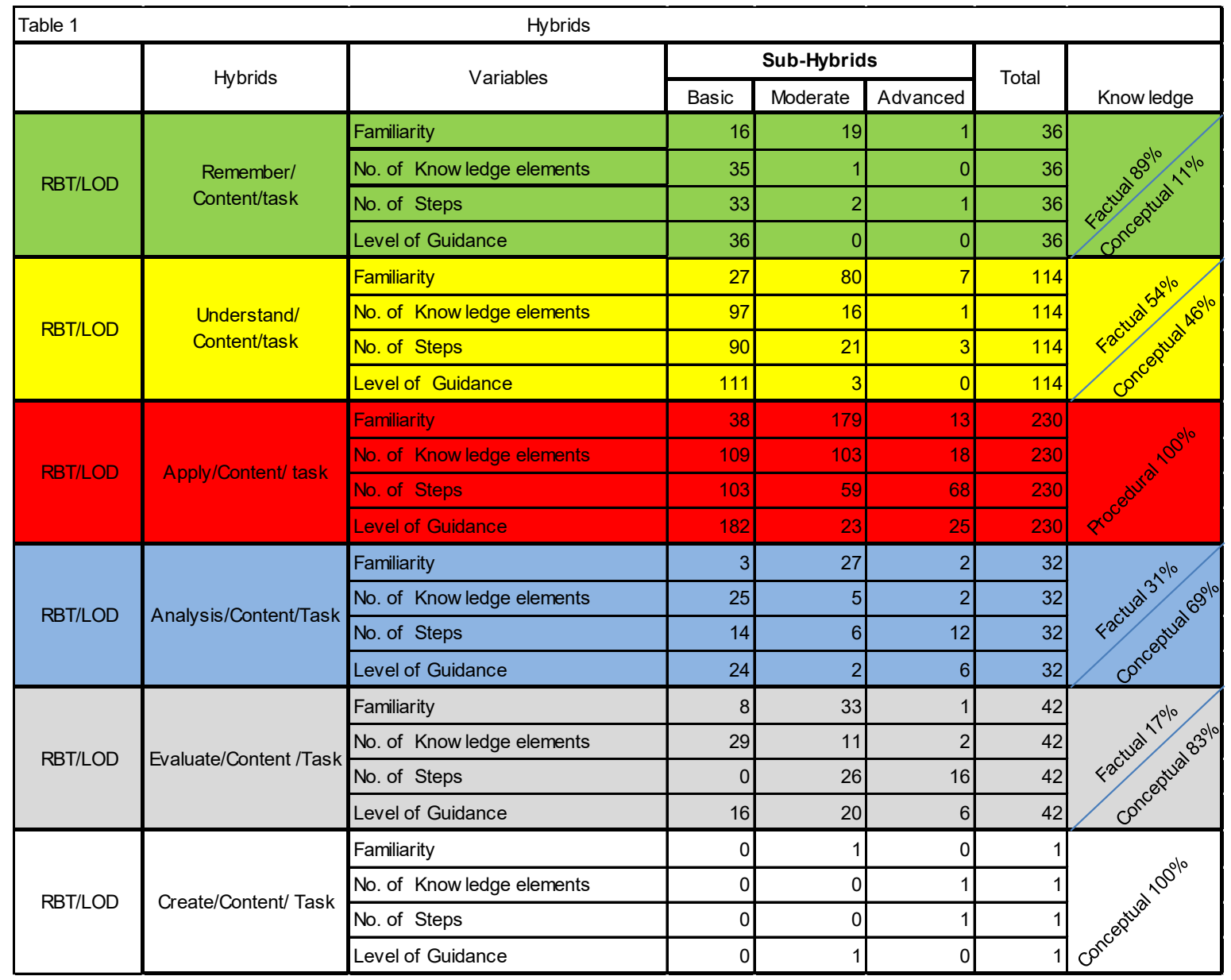




\section{Apply-Task-Hybrid (ATH)}

The prevalence of the ATH is also evident in the individual textbooks. In text X, it accounts for 46 per cent of the cognitive spread in the assessment activities, but totally dominates text $Y$ with 75 per cent coverage. Three assessments activities from text $\mathrm{X}$ and $\mathrm{Y}$ are presented below to provide insight into the way $\mathrm{CD}$ manifested.

Sample 1 (IT4 - TEXTBOOK X) Drawing from data given in the task, the instruction read: Calculate the depreciation per year. (Page 170)

Sample 2 (IT1 - TEXTBOOK Y) Based on information provided, the instruction read: Draw the provision for bad and doubtful debts account. (Page 84)

Sample 3 (EOC 1 - TEXT C) Based on information provided and the financial statements, students were required to:

"Compute six accounting ratios for both 1999 and 2000, which you feel would be of particular value in assessing the profitability and liquidity of Munyah Limited".

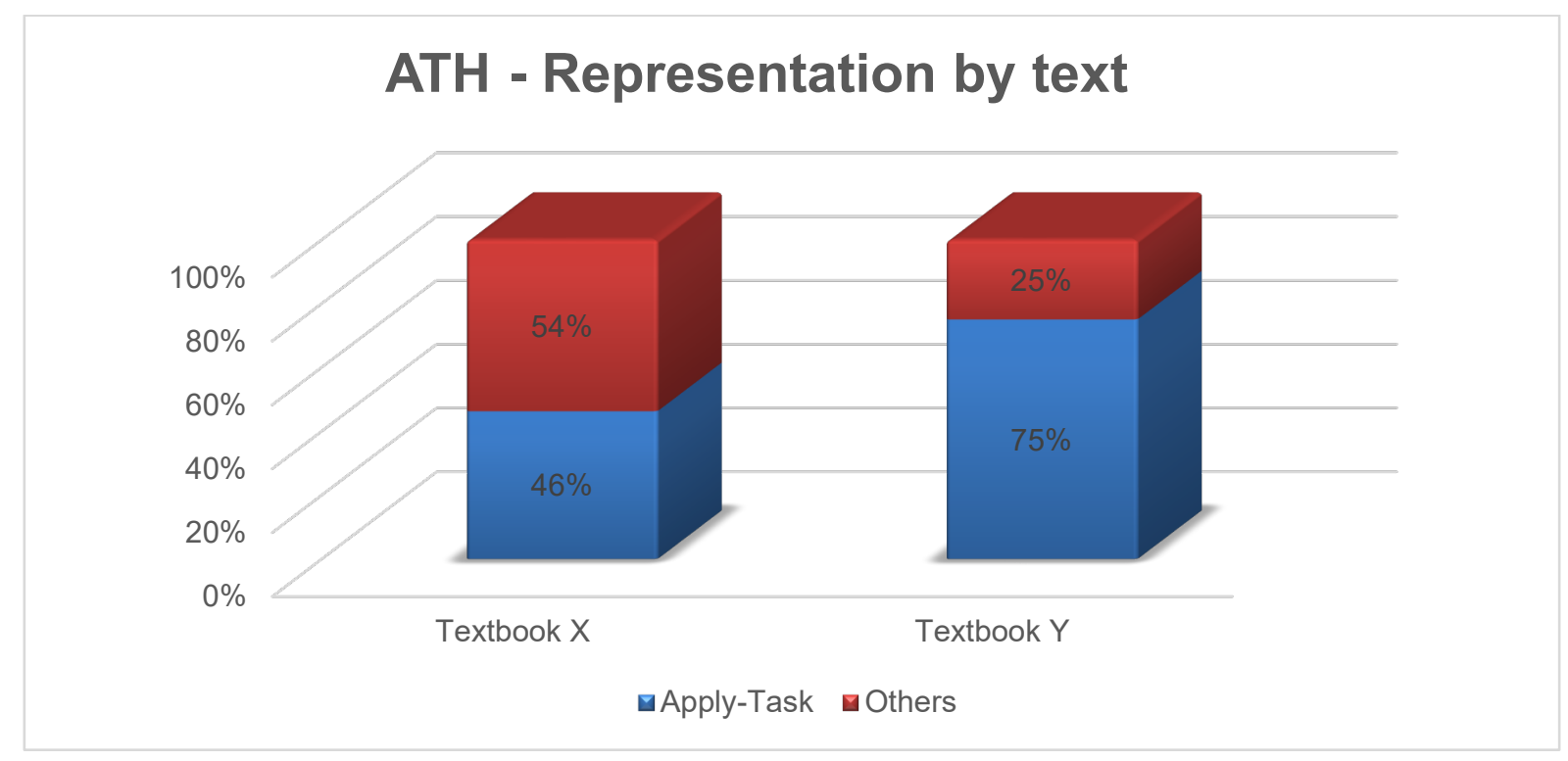

Figure 2: Apply-Task-Hybrid

The instruction provided in assessment tasks can be divided into two parts: the verb/verb phrase and the noun/noun phrase. The former addresses the cognitive requirement while the later relates to the applicable content. The active verbs in samples one and three are "calculate" and "compute". These require students to carry out different functions. To accomplish this task, they must use existing formulae for determining straight-line depreciation and the respective ratios that were given earlier in the text to the activities of Munyah Limited. This normally entails working with existing steps in order to obtain the accurate amount, that is usually predetermined. As such this question was sub-categorised as "execute" within the "Apply" 
cognitive level of the RBT. The same level of cognition is involved in resolving sample two above. To "draw up" ledger accounts requires students to adhere to established bookkeeping procedures using their existing knowledge on the subject-matter. Since the formats and procedures involved in the preparing these accounts are adequately defined, sample three also fell within "execute" in "Apply" category of the RBT.

The assessment activities discussed above describe the main attributes of the category "Apply". However, the volume of intellectual activity entailed in providing the satisfactory solution to each task varies considerably. The task parameter of the LOD provides greater understanding into the extent of cognitive variations associated with the required volume of work. The more the number of steps, the higher the demand on cognition. The calculation of depreciation required in sample one, basically entails two steps. In the first place, the student must work out the depreciable amount before s/he can ascertain the related expense for the period based on existing formula.

In order to resolve sample two satisfactorily, students need to follow three steps. Since the value of the required "provision for bad and doubtful debt" were not explicitly stated, individuals must determine the required figures via basic mathematical computations prior to the preparation of the general ledger accounts. However, the number of steps required to accomplish sample three accurately exceeds 4 steps. This question requires students to calculate 6 ratios for "1999" and "2000" employed in measuring the "profitability and liquidity" of Munyan Limited. By making use of exiting formulae, students ought to derive the accurate solutions to the relevant ratios. If the computation of each ratio is regarded as one step, it follows that the number of steps required to resolve this task accurately is not less than twelve. Our analysis also revealed assessment tasks that require up to 20 steps for a favourable outcome.

Although the cognitive process required to perform the above tasks are similar (Apply), the LAF clearly reveals added cognitive load emanating from the volume of work needed to satisfy the requirement of the respective assessment task. Assessment activities requiring many steps not only consumes more time, they also tend to be of greater complexity, thus requiring a more conscious and systematic approach (Arek-Bawa and Dhunpath 2017; Arek-Bawa 2018). Indeed, an individual's capacity to manage a substantial amount of information is closely linked with the level of cognitive difficulty (Davidson 1996; Jones and Wright 2012). Those with higher cognitive attributes have better capacity to handle huge quantum of information compared to others (Arek-Bawa 2018). It can therefore be inferred that the amount of work required in resolving an assessment activity is crucial in deciding the $\mathrm{CD}$ embedded within the assessment activity. 


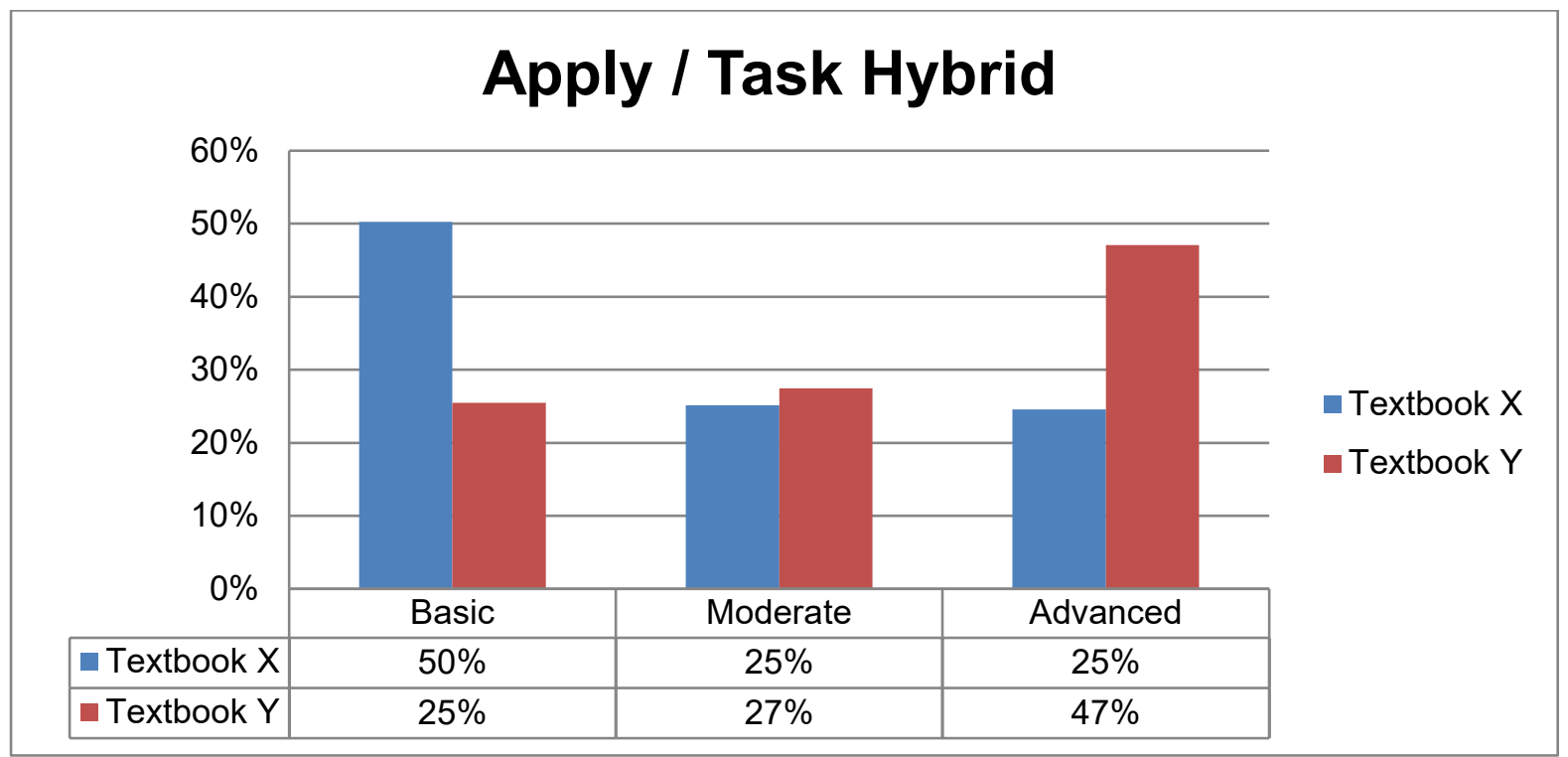

Figure 3: Apply-Task-Hybrid

In this article, we classified assessments that entailed a maximum of two steps for successful completion under "basic" sub-hybrid (see Figure 3). Where the task requirement exceeded four steps for successful resolution, they were tagged "advanced" and those in between were termed "moderate". Based on these sub-categories, our findings indicate that the majority of the assessment tasks in this category in textbook X fall within the Basic-Apply-Task sub-hybrid, while the Textbook Y tilts more on the Advanced-Apply-Task sub-hybrid.

Based on the above, and because 75 per cent of the assessment tasks falls within the ATH, one could argue that textbook Y is more cognitively demanding than textbook Y. Drawing from our argument, textbook $\mathrm{Y}$ is positioned to equip students to handle complex information because of the voluminous requirements in most of the assessment activities. With about 50 per cent of the assessment tasks pitched at the Basic sub-hybrid, textbook X appears to project less challenging activities. In mathematics, assessment tasks that involve simple application of algorithms are considered low level cognitive activities (Schneider et al. 2013). Following from this, it could be inferred that questions at the basic task application hybrid do not necessarily support middle order thinking; rather, they promote learning at lower levels of cognition.

Underlying each hybrid is the content prerequisite (Knowledge element). In this hybrid, our findings indicate that the underlying knowledge element being assessed is procedural knowledge, as seen in Table 1. From the examples cited, while the knowledge elements relate to the concepts of adjustments and ratios, these assessment tasks do not seek to ascertain the student's conceptual understanding, its effect or forms. Instead they seek to ascertain whether $\mathrm{s} /$ he can compute the relevant adjustment or ratios. They seek to assess the knowledge of "how" rather than "what"; in other words, "how" to calculate depreciation, ratios and prepare general 
ledger accounts. Because the required skills are mainly unique to the accounting domain, we have labelled these tasks under "knowledge of discipline-specific skills and algorithms" in the "Procedural Knowledge" category of the revised taxonomy.

\section{Understand-Content-Hybrid}

Following the ATH in terms of significance is the Understand-Content-Hybrid (UCH), which lies within the lower echelon of cognition which falls in the lower order thinking level. Using the RBT, questions in the Understand category require students to make meaning of what they have been taught or learnt from the textbook, as shown here under:

Sample 4: IT5 - Textbook X: Drawing from the data given in the question, the instruction read:

"What do we mean by the recoverable amount of the land"? (Page 362)

Sample 5: EOC 5 - Textbook Y: Based on information provided, the instruction read:

"State which accounting concepts the accountant should follow in dealing with each of the above problems and explain briefly what each concept means". (Page 31)

The active verbs in samples four and five are directly linked to the category Understand in the RBT or its sub-category. The verb "mean" from sample four can be deemed as the key word in defining the category - Understand i.e. "making meaning of instructional messages". The verb "explain" in sample five obviously lies within "explaining" subset which entails using a causality relationship to describe how a shift in one concept influences others. In this article, where one question contains two active verbs/verb phrases i.e. "state" and "explain", the question is categorised within the higher cognitive process in line with the assumption of the taxonomy.

In discussing this hybrid, we have not drawn on the task parameter of the LOD because its variables (number of steps and level of guidance) do not provide clear differentiation in the $\mathrm{CD}$ of the assessment tasks. Rather, the content parameter of the LOD provides deeper insight into the $\mathrm{CD}$ of the knowledge elements associated with $\mathrm{UCH}$.

The predominant knowledge elements in the $\mathrm{UCH}$ were factual knowledge accounting for 54 per cent of the content requirement of the tasks assessed together with conceptual knowledge at 46 per cent as indicated in Table 1. From sample four, "the recoverable amount of land" is an element of the measurement criteria of an asset; as such, it was classified under "knowledge of specific details and elements" as "Factual Knowledge". Factual knowledge encompasses disciplinary language. As previously mentioned, these are more or less the basic words, facts and relevant details peculiar to the accounting domain that every student aspiring to thrive in the discipline should be familiar with so that they can operate effectively as members of the 
accounting fraternity and provide solutions to questions that they may encounter (Arek-Bawa and Dhunpath 2017).

As the business language, accounting can be considered as the main avenue for communicating economic activities to interested users via the financial statements (Ho 2008; Ngwenya 2012; Torfason and Adorisio 2015). It engages a peculiar vocabulary which novice accounting students, especially those whose mother tongue differ from the dominant instructional language, can find daunting (Chatterjee and Brown 2012; Coetzee, Schmulian, and Kotze 2014). Consequently, O'Reilly-Bargate (2008) suggest that that disciplinary language be introduced gradually and systematically so that frequently used terms are presented earlier in the programme of instruction to enable more practice opportunities. Over half of the content assessed in the UCH address "Factual Knowledge", albeit in different proportions in the individual texts. However, as the knowledge element in sample five suggests, accounting concepts comes under "Conceptual Knowledge" within the subset of "knowledge of principles and generalisation".

Just like the ATH, the demand on knowledge element(s) was varied using two variables namely familiarity and number of knowledge elements. However, the outcome based on familiarity provided a wider spread and hence cognitive variation in this section will be discussed based on familiarity. Studies have shown that familiarity imparts the CD of assessment tasks (Le Hebel et al. 2017). Where students have had several opportunities to work with a particular concept, procedure or fact, they become conversant with such knowledge elements and are unlikely to find them challenging. In essence, topics that are introduced in the earlier part of the teaching programme are likely to be less challenging than those taught in the later part of the programme, as the students are more likely to have interacted with such concepts repeatedly. In this article, knowledge elements discussed in preceding chapters of the text were regarded as basic in terms of familiarity; those discussed in the chapter under consideration were termed moderate, while those discussed in subsequent chapters were regarded as advanced.

Based on these classifications, sample four was tagged under moderate familiarity while sample five was tagged as advanced because it relates to some concepts covered in subsequent chapters. For the novice accounting students, sample five will be rather daunting because they may not have heard of "Last-in-first-out", "First-in-first-out", "liquidation" or the different adjustments pertaining to the different concepts assessed. For students to address the problem, they would have to adapt existing knowledge base drawing from a broad understanding of the concept to provide probable answers (Anderson et al. 2001). In attempting to find a solution, most students draw on their problem-solving capabilities to resolve problems that they are not 
familiar with (Arek-Bawa 2018). Previous studies by scholars including Rassaei (2015) indicated that people with strong problem-solving skills tackle unfamiliar issues better than others.

As depicted in Figure 4, assessment tasks addressing contents presented in the current chapter sub-categorised in the moderate sub-hybrid, dominated the UCH accounting for 70 per cent of the total. While these tasks may not necessarily elicit problem-solving abilities, insufficient practice opportunities make such questions more difficult to address. Both texts also contain a fair share of the questions at the basic sub-hybrid that that can be easily understood by college students due to repeated engagement with such accounting terms or concepts. Although the demand on cognition may be deemed low, practice activities within the basic sub-hybrid are beneficial in developing the students' confidence in their work due the ease of successful completion. In total, only seven questions elicited students' abilities to comprehend unfamiliar tasks.

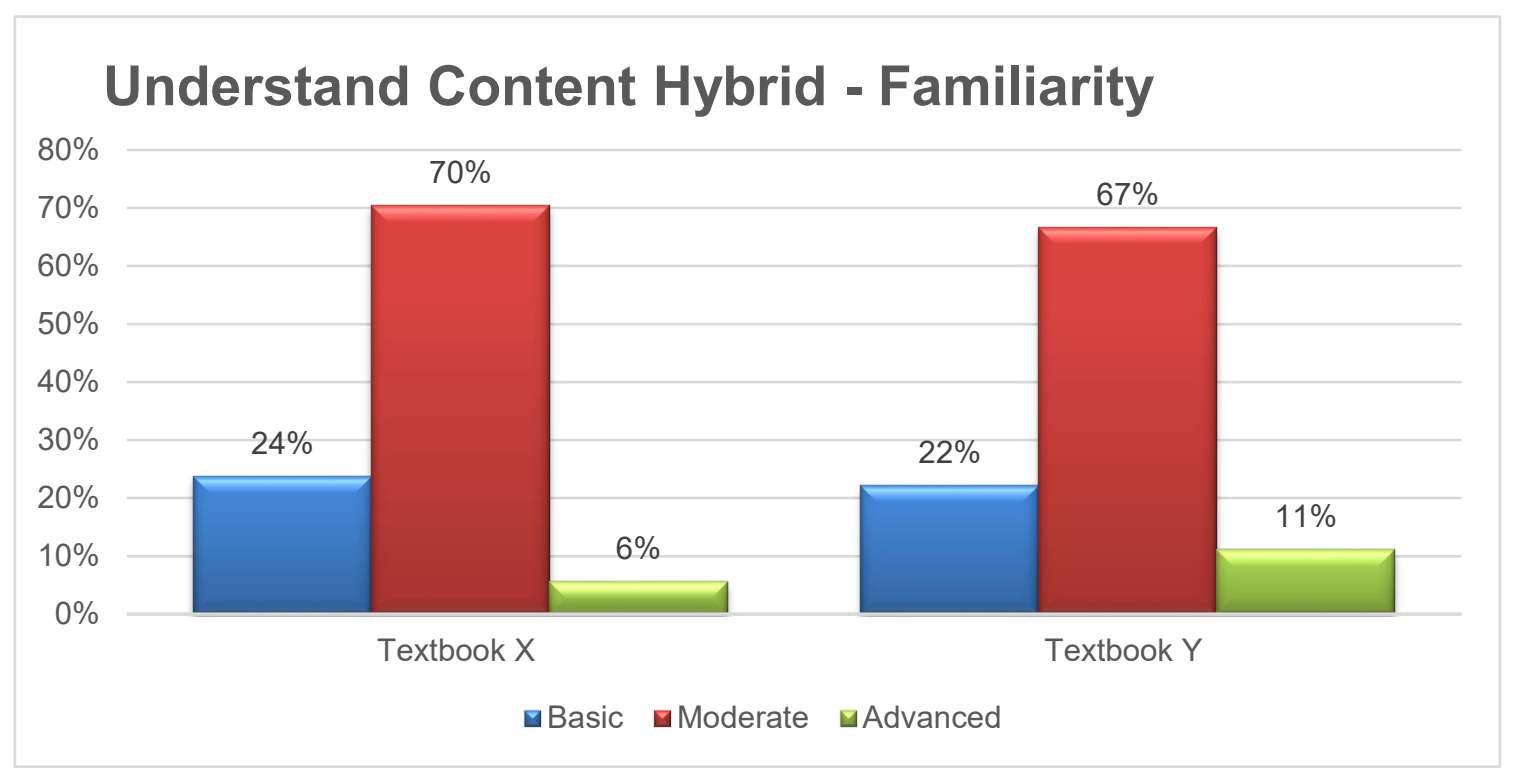

Figure 4: Understanding-Content-Hybrid

\section{Evaluate-Content-Hybrid (ECH)}

The third major hybrid using the LAF was the ECH. This hybrid which falls within the higher thinking order accounts for nine percent of the total assessment tasks analysed. These assessment tasks require students to make judgement, give advice or critique a decision or plan. Samples of such tasks analysed in both textbooks are seen below:

Sample 6: EOQ 4B - Textbook Y: Based on Financial Statements, ratios and relevant information, the instruction read:

"Using the summarised accounts given above and ratios you have just calculated, comment on 


\section{Sample 7: QB 3.3b - Textbook X}

"Would you combine the value of car A with car B in a category called "luxury cars" on the face of the statement of financial position? Justify your answer". (Page 105)

Sample six requires students to comment or give their opinion on the state of affairs and future of Mwangaza Ltd. To proffer a satisfactory solution to this question, it is essential for students to understand what each ratio calculated in the previous section stands for, then interpret these ratios considering certain criteria such as the previous year's ratio, before they can make reasonable comments. The reasonableness of the comment is founded on soundness of the criteria. Since the criteria are internal, sample six was placed under "checking" in the category "Evaluate. Similarly, sample seven, which requires students to provide a motivation for the possible classification of luxury vehicles, is sub-categorised under "Checking", as they will be drawing on the standards of financial reporting.

The content requirement in the ECH is predominantly conceptual knowledge, which accounts for 86 per cent of the content within this hybrid. This is a form of declarative knowledge embodying accounting "concepts, principles, models, or theories" (Anderson et al. 2001, 42). They are broader bodies of knowledge that encompass accounting terms and facts. Also termed disciplinary knowledge, conceptual knowledge demonstrate how diverse concepts and / or facts are interrelated. These authors maintain that an in-depth conceptual understanding usually implies proficiency in any field. The content requirement in sample six pertains to the financial positions and prospects of Mwangaza Ltd. For one to comment effectively, s he must be conversant with the concepts of ratios to identify ratios that address the state of affairs of the business and its future success. A thorough understanding of this concept is needed to identify and discuss areas of weaknesses and strength within the business, with a view to providing reasonable comments. Such concepts fall within "knowledge of principles and generalisation" in "Conceptual Knowledge". Sample seven, that requires student's views on the depiction of luxury vehicles as a category in the financial statement, was placed under "knowledge of classifications and categorisation".

Within the $\mathrm{ECH}$, the content element was further analysed via the number of knowledge elements criteria because it offered a broader cognitive variation. About 69 per cent of the assessments reviewed in both textbooks address one knowledge element. In essence, an individual can work out an accurate solution to these questions drawing from a thorough comprehension of the relevant topic or subject matter. These are considered relatively easier to accomplish as they require focus on only one subject-matter. In contrast, where the assessment 
tasks require knowledge of two or more topics, it is usually more difficult as they involve certain degree of integration of relevant content. As the number of content requirement increases, the assessment activity becomes more difficult (Ahmed and Pollitt 1999; Zingaro, Petersen and Craig 2012; Arek-Bawa 2018), as it becomes important to demonstrate how one item integrates into the other and its effect on the other. The capability to consider and comprehend interrelationships is tantamount to qualitative learning (Biggs and Tang 2007). The structure of observed learning outcomes taxonomy places the integrative skills at the uppermost cognitive levels i.e. the "Relational and the Extended Abstract levels" (Biggs and Collies 1982).

With the ECH, assessments focused on a single content were labelled "basic" as their demand on cognition is low since the emphasis is on one topic or subject matter (Zingaro, Petersen and Craig, 2012; Arek-Bawa 2018). Those that required knowledge of two concepts were tagged "moderate", while other assessment tasks addressing more than two content requirements for successful completion, were termed advanced. In all, the "moderate" evaluate content subset accounted for 26 per cent of the total tasks assessed, while 5 per cent was categorised as "advanced".

Within the individual textbooks, the situation is not too different, as shown in Figure 5, except that all the questions from text $\mathrm{Y}$ address only one knowledge element at basic subhybrid.

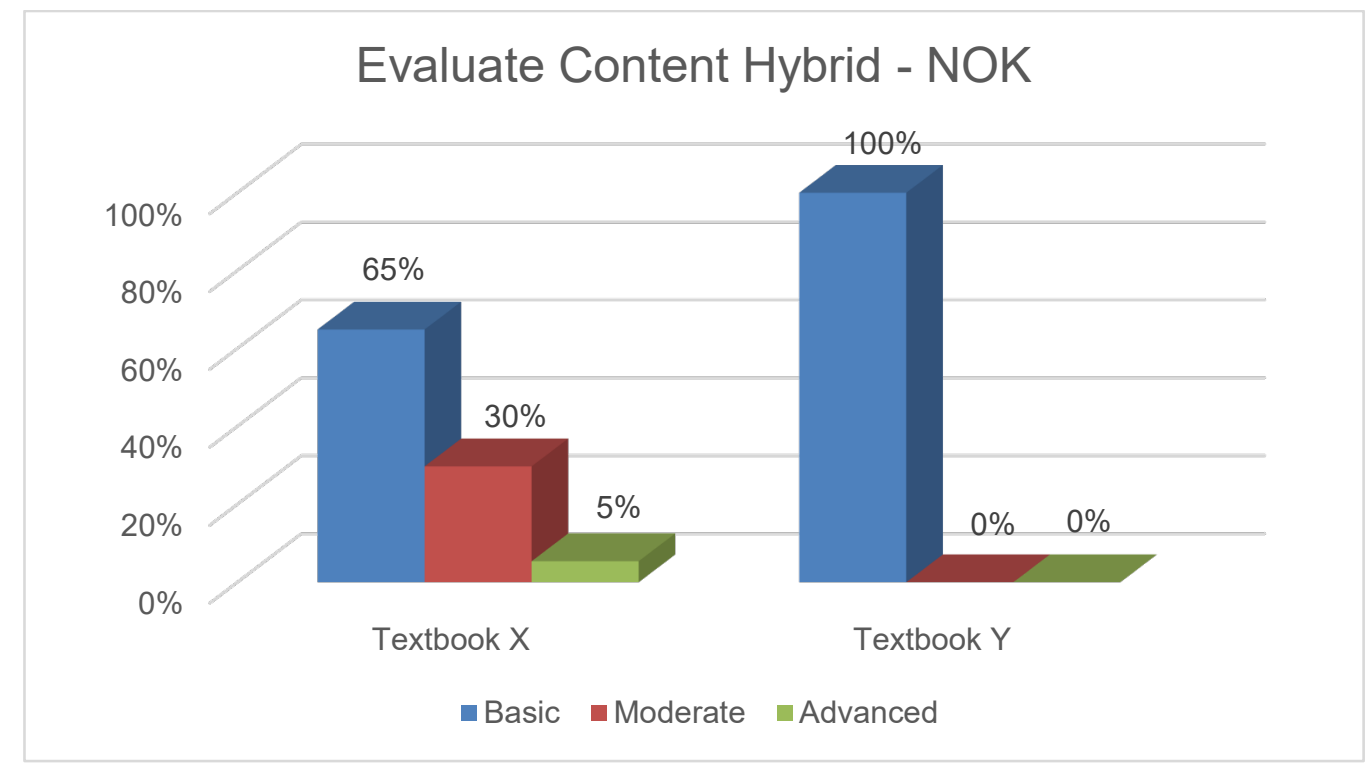

Figure 5: Evaluate-Content hybrid

Within the individual textbooks, the situation is not too different, as shown in Figure 5, except that all the questions from text $\mathrm{Y}$ address only one knowledge element at basic sub-hybrid. 
While 35 per cent of the assessment activities contained in textbook $\mathrm{X}$ offer students the opportunity to integrate knowledge and handle inter-relationships amongst different knowledge elements, textbook Y does not. This outcome of textbook Y mirrors Howieson (2003)'s remark on his study on intermediate accounting courses that the accounting contents are presented separately with minimal integration; therefore, he asserts that college students are unlikely to gain an "inquiring mind".

\section{Other hybrids}

The hybrids with least representation within both textbooks relate to the Remember $(8 \%)$, Analyse (7\%) and Create (0\%) cognitive levels. Indeed, in textbook Y, there are only three assessment tasks at the Remember level, with no representation in the other two levels. Textbook X gives a wider spread of cognitive representation, with about 17 per cent of the total task therein assessing students' ability to differentiate data, with the aim of finding relationships therein, and their ability to recall learned information. There was only one task pitched at the Create level in textbook $\mathrm{X}$ aimed at addressing the creative skills of students. The task required students to write a letter to management incorporating some ratios in view of a planned issue of a prospectus for new shares. The task is placed under this category because it requires learners to do something new and relatively different, which is letter writing. It involves synthesizing information into an integrated whole in view of the prospectus, hence it was classified under Create.

\section{CONCLUSION}

The findings of this study indicate that assessment tasks in level-one Financial Accounting textbooks primarily promotes the ability to transfer learning under the category Apply within the middle-level in the cognitive hierarchy. The low level of assessment tasks addressing higher cognitive skills could mean that the textbooks fall short in preparing students for practice because they are not equipped to decide on real life issues, solve unfamiliar problems and develop unique solutions to address diverse problems. In other words, it could be argued that the objectives of the higher education accounting curriculum are not completely fulfilled through textbooks. However, based on our argument that assessments activities requiring complex and multiple steps for adequate resolution place higher demands on cognition, it follows that certain textbooks pitched at lower or middle level of cognition contribute to developing high cognitive skills. A typical example is textbook $\mathrm{Y}$, which is dominated by assessment tasks that fall within the Apply (75\%) cognitive level, with 46 per cent subcategorised within the advanced ATH sub-hybrid. These assessment tasks, though at middle 
level of cognition, will aid students in developing complex cognitive attributes. Therefore, academics and producers of textbooks who are able to incorporate assessment tasks with voluminous steps covering three or more content areas, can actually aid students in acquiring abilities to enable them to handle the complexities of the real world.

Nonetheless, our argument does not in any way negate the need for accounting textbooks to include assessment tasks that address different levels of cognition in a fair proportion. The base could be in the proportion laid out in the South African curriculum and assessment policy statements: lower-level - 30 per cent; middle-level - 40 per cent; higher-level - 30 per cent, for Accounting. Because learning to a greater extent is influenced by assessments (Biggs 2003), such tasks will go a long way to equip students with analytical, creative and critical thinking skills to prepare them to contribute effectively in the work environment.

The results of this research confirm that of earlier studies (Davidson and Baldwin 2005; Gupta and Marshall 2010; Stokes, Rosetti and King 2010), in the sense that the majority of the assessment tasks address middle level skills. This may well be adduced to the rule-based nature of the subject (Gupta and Marshall 2010), and/or the necessity for entry level students to become proficient in rudimentary bookkeeping techniques needed in preparing journals, ledgers and annual financial reports that serves as the base to support future learning. Nevertheless, some authors contend that accounting education at any level in the undergraduate programme ought to aid students in acquiring a diverse range of intellectual abilities including those in the higher echelon (Lubbe 2014; Arek-Bawa 2018).

This article provides insight to professional accounting institutions, higher education institutions and accounting academics, who aim for high intellectual abilities in students. In view of this outcome, accounting academics who depend on these textbooks should be more thoughtful in selecting assessment tasks to aid learning. Where possible, academics may consider developing their own assessment tasks or incorporating appropriate tasks from other sources to augment those found in the texts (Arek-Bawa and Dhunpath 2017). The need for producers of accounting texts to integrate a fair amount of assessment activities which build high reasoning abilities need not be overstated, especially in the African context. While some academics have access to other sources of assessment materials, the same cannot be said in countries battling with a steady supply of electricity and internet connectivity. Therefore, the need to enhance the quality of this competitive tool to facilitate higher levels of learning becomes imperative. Assessment tasks could also be varied to include those with voluminous requirements, which are unfamiliar and with more than one knowledge element, to develop higher cognitive attributes.

Our article is limited in certain areas. The results are based on our analysis of four chapters 
in two prescribed textbooks used by first-year Accounting students from two countries in SubSaharan Africa. It is likely that a wider coverage could produce a different outcome. Furthermore, we used the LAF that provided deeper insight into nuances in cognition that may not be observed via other frameworks. In addition, the assumption that entry level students were yet to engage with accounting in an academic capacity, may not hold for all students. Interested scholars can consider these research questions: What explains the cognitive representation of assessment tasks in accounting textbooks used across all levels of study? Others may consider how the cognitive representation of assessment tasks compares amongst three first-year accounting text used by universities based in one country in the African continent. Undoubtedly, these studies will add to our understanding and capacity to produce learning materials to develop higher cognitive attributes.

\section{ACKNOWLEDGMENT}

Our sincere thanks go to the UKZN PhD higher education cohort and Writer's Retreat Workshop for their invaluable critique, training and motivation that have contributed to the success of this article.

\section{REFERENCES}

Ahmed, A. and A. Pollitt. 1999. Curriculum demands and question difficulty. Paper presented at the IAEA conference, Bled, Slovenia.

Agrawal, R., S. Gollapudi, K. Kenthapadi, N. Srivastava and R. Velu. 2010. Enriching textbooks through data mining. Paper presented at the Proceedings of the First ACM Symposium on Computing for Development.

Agrawal, R., S. Gollapudi, A. Kannan and K. Kenthapadi. 2011. Identifying enrichment candidates in textbooks. Paper presented at the Proceedings of the 20th international conference companion on World wide web.

Anderson, L. W., D. R. Krathwohl, P. W. Airasian, K. A. Cruikshank, R. E. Mayer, P. R. Pintrich, ... M. C. Wittrock. 2001. A taxonomy for learning, teaching, and assessing: A revision of Bloom's taxonomy of educational objectives. (Abridged edition). White Plains, NY: Longman.

Arek-Bawa, O. and R. Dhunpath. 2017. Aessessment and cognitive demand in higher education accounting textbooks. Alternations 24(2): 140-166.

Arek-Bawa, O. 2018. Cognitive demand of assessment activities in level-one financial accounting textbooks in selected African countries. Doctoral dissertation, University of KwaZulu-Natal, Durban.

Bargate, K. 2012. Criteria considered by accounting faculty when selecting and prescribing textbooks a South African study. International Journal of Humanities and Social Science 2(7): 114-122.

Berger, M., L. Bowie and L. Nyaumwe. 2010. Taxonomy matters: Cognitive levels and types of mathematical activities in mathematics examinations. Pythagoras 2010(71): 30-40.

Bezuidenhout, M. and H. Alt. 2011. "Assessment drives learning": Do assessments promote high-level cognitive processing? South African Journal of Higher Education 25(6): 1062-1076.

Biggs, J. 2003. Aligning teaching and assessing to course objectives. Teaching and Learning in Higher Education: New Trends and Innovations 2: 13-17. 
Biggs, J. B. and K. F. Collies. 1982. Evaluating the quality of learning: The structure of the observed learning outcome taxonomy. Academic Press, New York.

Biggs, J. and C. Tang. 2007. Teaching for quality learning at university: What the student does. Philadelphia, Pa.: Society for Research into Higher Education: Open University Press.

Chatterjee, B., and A. Brown. 2012. Instructional note: Embedding English language in an accounting subject: A case of interactive interdisciplinary collaboration and learning. E-Journal of Business Education \& Scholarship of Teaching 6(1): 44-50.

Chiang, W. C., T. D. Englebrecht, T. J. Phillips Jr. and Y. Wang. 2008. Readability of financial accounting principles textbooks. The Accounting Educators' Journal 18: 47-80.

Coetzee, S. A., A. Schmulian and L. Kotze. 2014. Communication apprehension of South African accounting students: The effect of culture and language. Issues in Accounting Education 29(4): 505-525. doi:10.2308/iace-50850.

Commission for University Education. 2014. Universities standards and guidelines. 2014. http://www.cue.or.ke/index.php/downloads/category/6 standards-and-guidelines

CUE see Commission for University Education.

Davidson, R. A. 1996. Cognitive complexity and performance in professional accounting examinations. Accounting Education 5(3): 219.

Davidson, R. A. and B. A. Baldwin. 2005. Cognitive skills objectives in intermediate accounting textbooks: Evidence from end-of-chapter material. Journal of Accounting Education 23(2): 79 95.

Elo, S., M. Kääriäinen, O. Kanste, T. Pölkki, K. Utriainen and H. Kyngäs. 2014. Qualitative content analysis. Sage Open 4(1): 2158244014522633.

Forman, J. and L. Damschroder. 2008. Qualitative content analysis. Empirical research for bioethics: A primer, 39-62. Oxford, UK: Elsevier Publishing.

Greaney, V. 2006. Textbooks, respect for diversity, and social cohesion. PROMOTING 47.

Gupta, S. and L. L. Marshall. 2010. Congruence between entry-level accountants' required competencies and accounting textbooks. Academy of Educational Leadership Journal 14(1): 112.

Henningsen, M. and M. K. Stein. 1997. Mathematical tasks and student cognition: Classroom-based factors that support and inhibit high-level mathematical thinking and reasoning. Journal for Research in Mathematics Education, 524-549.

Ho, H. 2008. Spiraling effect of prior knowledge in accounting studies. International Journal of Learning 15(4): 25-29.

Howieson, B. 2003. Accounting practice in the new millennium: Is accounting education ready to meet the challenge? The British Accounting Review 35(2): 69-103.

IAESB see International Accounting Education Standards Board.

International Accounting Education Standards Board. 2010. Handbook of international education pronouncements. 2010 Edition: International Federation of Accountants (IFAC) New York, NY.

Jones, S. H. and R. A. Davidson. 2007. Measuring the problem-solving abilities of accounting and other business students: A comparison and evaluation of three methods. Accounting Education: An International Journal 16(1): 65-79. doi:10.1080/09639280600826034

Jones, S. H. and M. E. Wright. 2012. Does cognitive style affect performance on accounting examination questions? Global Perspectives on Accounting Education 9: 31.

Kasule, D. 2011. Textbook readability and ESL learners. Reading \& Writing-Journal of the Reading Association of South Africa 2(1): 63-76.

Le Hebel, F., P. Montpied, A. Tiberghien and V. Fontanieu. 2017. Sources of difficulty in assessment: Example of PISA science items. International Journal of Science Education 39(4): 468-487.

Leong, S. C. 2006. On varying the difficulty of test items. Paper presented at the 32nd Annual 
Conference of the International Association for Educational Assessment in Singapore.

Lubbe, I. 2014. Special Report: Accounting education A new way forward. ASA Accountancy South Africa, CAISA.

Mahadi, M. A., and M. Shahrill. 2014. Identifying the issues from history textbooks research. In Abstracts and Proceedings of the International Conference on Social Sciences and Humanities, 904-911. Istanbul, Turkey.

Marsh, E. E. and M. D. White. 2006. Content analysis: A flexible methodology. Library Trends 55(1): $22-45$.

Ngwenya, J. C. 2012. Formative assessment in accounting: Exploring teachers' understanding and practices. Doctoral dissertation, University of KwaZulu-Natal, Durban.

Okafor, R. G. 2012. Accounting education in Nigerian universities: Challenges and prospects. Journal of Economics and Sustainable Development 3(14): 205-212.

Opoku-Amankwa, K. 2010. What happens to textbooks in the classroom? Pupils' access to literacy in an urban primary school in Ghana. Pedagogy, Culture \& Society 18(2): 159-172.

O'Reilly-Bargate, K. 2008. An investigation of prescribed managerial accounting and finance textbooks used by B.Com accounting students at some universities in South Africa. Masters thesis, University of KwaZulu-Natal, Durban.

Park, A. M. 2011. Comparing the cognitive demand of traditional and reform Algebra 1 Textbooks. Project, Harvey Mudd College, California.

Rassaei, E. 2015. Recasts, field dependence/independence cognitive style, and L2 development. Language Teaching Research 19(4): 499-518.

SAICA see The South African Institute of Chartered Accountants.

SAQA see The South African Qualifications Authority

Schneider, M. C., K. L. Huff, K. L. Egan, M. L. Gaines and S. Ferrara. 2013. Relationships among item cognitive complexity, contextual demands, and item difficulty: Implications for achievement-level descriptors. Educational Assessment 18(2): 99-121.

Schultz, K. T. 2009. Cognitive demand and technology use in high school mathematics teachers' selection and implementation of tasks. Doctoral dissertation, University of Georgia.

Sheard, J., A. Carbone, D. Chinn, T. Clear, M. Corney, D. D’Souza, ... and D. Teague. 2013. How difficult are exams? A framework for assessing the complexity of introductory programming exams. In Proceedings of the Fifteenth Australasian Computing Education Conference, Volume 136, 145-154. Australian Computer Society, Inc., Australia.

Stokes, L. 2008. A preliminary study of learning objectives across the curriculum: An analysis of various accounting textbooks. Advances in Accounting Education 9: 307-326.

Stokes, L., J. L. Rosetti and M. King, M. 2010. Form over substance: Learning objectives in the business core. Contemporary Issues in Education Research (CIER) 3(11): 11-20.

The South African Institute of Chartered Accountants. 2017. Competency framework detailed guideline for academic programme. http://www.saica.co.za/Portals/0/LearnersStudents/documents/ Competency\%20Framework\%202019.pdf

The South African Qualifications Authority. 2012. Level of descritors for the South African National Qualification framework. http://www.saqa.org.za/docs/misc/2012/level_descriptors.pdf

Torfason, A. B. and A. L. M. Adorisio. 2015. Accounting as the language of business? Paper presented at the IPA Conference 2015.

Zingaro, D., A. Petersen and M. Craig. 2012. Stepping up to integrative questions on CS1 exams. In Proceedings of the 43rd ACM technical symposium on Computer Science Education, 253-258. 